\title{
Nrf2 target genes are induced under marginal selenium-deficiency
}

\author{
Mike Müller · Antje Banning • Regina Brigelius-Flohé • \\ Anna Kipp
}

Received: 28 August 2009/Accepted: 10 January 2010/Published online: 29 January 2010

(C) Springer-Verlag 2010

\begin{abstract}
A suboptimal selenium supply appears to prevail in Europe. The current study, therefore, was focused on the changes in gene expression under a suboptimal selenium intake. Previous microarray analyses in the colon of mice fed either a selenium-adequate or a moderately deficient diet revealed a change in genes of several pathways. Severe selenium-deficiency has been found previously to influence Nrf2-regulated genes of the adaptive response. Since the previous pathway analyses were done with a program not searching for Nrf2 target genes, respective genes were manually selected and confirmed by qPCR. qPCR revealed an induction of phase II (Nqo1, Gsts, Sult1b1 and Ugt1a6) and antioxidant enzymes (Hmox1, Mt2, Prdx1, Srxn1, Sod1 and Gclc) under the selenium-poor diet, which is considered to compensate for the loss of selenoproteins. The strongest effects were observed in the duodenum where preferentially genes for antioxidant enzymes were up-regulated. These also include the mRNA of the selenoproteins TrxR1 and GPx2 that would enable their immediate translation upon selenium refeeding. The down-regulation of Gsk $3 \beta$ in moderate selenium-deficiency observed in the previous paper provides a possible explanation for the activation of the Nrf2 pathway, because inhibition of GSK3 $\beta$ results in the nuclear accumulation of Nrf2.
\end{abstract}

M. Müller · R. Brigelius-Flohé · A. Kipp ( $₫)$

Department Biochemistry of Micronutrients,

German Institute of Human Nutrition Potsdam-Rehbruecke,

Arthur-Scheunert-Allee 114-116, 14558 Nuthetal, Germany

e-mail: annakipp@dife.de

\section{A. Banning}

Biochemical Institute, Justus Liebig University Giessen, 35392 Giessen, Germany
Keywords Selenium · Nrf2 Phase II enzyme · Intestine $\cdot$ Oxidative stress

$\begin{array}{ll}\text { Abbreviations } & \\ \text { GST } & \text { Glutathione S-transferase } \\ \text { NQO1 } & \text { NADPH:quinone oxidoreductase } \\ \text { HMOX1 } & \text { Heme oxygenase 1 } \\ \text { Trsp } & \text { Gene encoding for selenocysteine tRNA } \\ \text { Nrf2 } & \text { NF-E2-related factor } \\ \text { ARE/EpRE } & \text { Antioxidant or electrophilic response } \\ & \text { element } \\ \text { GSH } & \text { Glutathione } \\ \text { ROS } & \text { Reactive oxygen species } \\ \text { RDA } & \text { Recommended daily allowance } \\ \text { GPx } & \text { Glutathione peroxidase } \\ \text { TrxR (Txnrd) } & \text { Thioredoxin reductase }\end{array}$

\section{Introduction}

In mammals, the essential trace element selenium exerts its function as selenocysteine incorporated into the active center of selenoproteins. In humans, 25 genes encode for selenoproteins [30]. Many of these are involved in redox processes [35], including glutathione peroxidases (GPx) [8] and thioredoxin reductases (TrxR) [14]. A marginal selenium-deficiency, as present in the European population, is possibly accompanied by a slightly increased oxidative status [45].

Expression of selenoproteins depends on the cellular selenium status. However, several microarray studies revealed that the expression of also non-selenoproteins is influenced by the availability of selenium (reviewed in [13]). Underlying mechanisms are still scarce. Genes often 
influenced by the selenium status code for enzymes of the antioxidant defense and the phase II system [13, 44]. On the one hand, large doses of selenium stimulate the activity of phase II enzymes like glutathione S-transferase (GST) and NADPH:quinone oxidoreductase (NQO1). This effect can be mediated by selenocysteine Se-conjugates [53] and dimethyl diselenide [58], respectively. On the other hand, there is strong evidence for an induction of antioxidant and phase II enzymes in selenium-deficiency. Already in the late 1970s, it was reported that heme oxygenase 1 (HMOX1) [12] as well as GST activity were elevated in selenium-deficient rat liver [32]. The idea of a compensatory up-regulation of antioxidant and phase II enzymes in selenium-deficiency was further supported by findings in mice with an organ-specific targeted removal of the gene encoding for selenocysteine tRNA (Trsp). The complete loss of selenoproteins in liver resulted in the induction of GSTPi, NQO1 and HMOX1 [52].

Most of the genes for proteins involved in the cellular antioxidant defense and in phase II detoxification are regulated via the redox- and electrophile-sensitive transcription factor NF-E2-related factor (Nrf2) (reviewed in [16]), which binds to the cis-acting antioxidant or electrophilic response element (ARE/EpRE) $[48,56]$. Nrf2 $2^{-/-}$mice are sensitive to chemical-induced toxicity and tumorigenesis [43]. Additionally, $\mathrm{Nrf} 2^{-/-}$mice are highly susceptible to oxidative stress [1] and have a lower basal glutathione (GSH) level [47]. Under unstimulated conditions, Nrf2 is kept in the cytosol bound to Keap1, which functions as a substrate adaptor for a Cul3-based E3 ubiquitin ligase and targets Nrf2 for degradation. Transactivation of target genes is induced in response to reactive oxygen species (ROS) or electrophilic agents that modify susceptible thiol groups of Keap1, resulting in a rapid increase in nuclear Nrf2 protein levels (reviewed in [38]). A simultaneous disruption of Trsp and Nrf2 abolished the induction of phase II enzymes, thus, verifying the role of Nrf2 in responding to the loss of selenoproteins [52]. The ARE-driven reporter gene activity in ARE-reporter mice fed a selenium-deficient diet was strongly enhanced compared to mice fed the control diet [9]. In addition, the increased GST and NQO1 activity observed in selenium-deficient wild type mice was not detectable in $\mathrm{Nrf} 2^{-1-}$ mice [9]. This provided the first direct link between dietary selenium-deficiency and Nrf2 activation.

Based on these results, the current study was focused on the influence of a marginal selenium-deficient diet on the expression of Nrf2-regulated genes. The selenium-poor diet contained half the recommended daily allowance (RDA) of mice [28], reflecting a physiological situation which can equally occur by changing nutritional habits or by seasonal food variation. The target organs analyzed were the intestinal sections colon and duodenum, the first line of defense against xenobiotic stress, as well as liver, which highly expresses phase II enzymes. Pathway analysis of the microarray data obtained in the previous study [28] did not indicate the Nrf2 pathway as being affected since the used program GenMAPP does not include a MAPP (microarray pathway profile) for this pathway. Therefore, 48 Nrf2 target genes and 12 classical phase II enzymes were manually identified, and interesting candidate genes were confirmed by qPCR.

\section{Materials and methods}

\section{Animal experiment}

Tissue samples were obtained from the animals treated as reported previously [28]. Briefly, male C57BL/6 J mice (34 weeks of age) were fed either a selenium-poor $(0.086 \mathrm{mg}$ $\mathrm{Se} / \mathrm{kg})$ or a selenium-adequate diet $(0.15 \mathrm{mg} \mathrm{Se} / \mathrm{kg})$ produced by mixing selenomethionine (Acros, Geel, Belgium) into the poor one (Altromin, Lage, Germany). After a 6-week feeding period, anesthetized animals were killed by cervical dislocation. Plasma and tissues freeze-clamped in liquid nitrogen were stored at $-80^{\circ} \mathrm{C}$. The selenium status of the 12 animals per group was characterized by the plasma selenium content and liver GPx activity and found to be decreased under moderate selenium-deficiency to 13 and $35 \%$ of selenium-adequacy, respectively [28].

\section{RNA isolation}

Tissue was ground under cooling with liquid nitrogen. 20$30 \mathrm{mg}$ powder was suspended in $800 \mu \mathrm{l}$ of cold Trizol (Invitrogen, Karlsruhe, Germany) and homogenized with a tissue lyzer (Qiagen, Hilden, Germany) for $2 \times 2 \mathrm{~min}$ at $30 \mathrm{~Hz}$. RNA was isolated using the Trizol protocol according to the manufacturer's instructions. Genomic DNA was digested with $10 \mathrm{U}$ RQ1 DNase (Promega, Mannheim, Germany), and RNA was cleaned up by phenol-chloroform extraction. RNA concentrations were measured using a NanoDrop ND-1000 (Peqlab Biotechnologie GmbH, Erlangen, Germany).

\section{Microarray analysis}

The microarray analysis using Mouse $44 \mathrm{~K}$ microarrays (Agilent Technologies, Böblingen, Germany) was done as described previously [28]. Significantly regulated genes were identified with Student's $t$-test $(P<0.05)$.

Quantitative real-time PCR

RNA $(3 \mu \mathrm{g})$ was reversely transcribed with 150 fmol oligo(dT)15 primers and $180 \mathrm{U}$ Moloney murine leukemia 
virus reverse transcriptase (Promega) in a total volume of $45 \mu$. Real-time PCRs (Mx3005PTM QPCR System, Stratagene, Amsterdam, Netherlands) were performed in triplicates with $1 \mu \mathrm{l}$ of tenfold diluted cDNA in $25-\mu 1$ reaction mixtures using SYBR Green I (Molecular Probes, Eugene, USA) as fluorescent reporter. The annealing temperature was 60 and $62^{\circ} \mathrm{C}$, respectively, for all PCR reactions (Table 1$)$. PCR products were quantified with a standard curve ranging from $1 \times 10^{3}$ to $1 \times 10^{9}$ copies of each amplicon. Primers (Table 1, Sigma-Aldrich, Taufkirchen, Germany) were designed to be specific for cDNA by placing at least one primer onto an exon/intron boundary with PerlPrimer v1.1.14. The mean of the reference genes Rpl13a and Hprt1 was used for normalization of qPCR results in the colon and liver, whereas Rpl13a was used solely in the duodenum.

Preparation of tissue lysates

$10 \mathrm{mg}$ of ground tissue was suspended in $250-\mu 1$ homogenization buffer (100 mM Tris- $\mathrm{HCl}, 300 \mathrm{mM} \mathrm{KCl}, 0.01 \%$ Triton X-100) containing $2 \mu$ l of protease inhibitor cocktail III (Calbiochem, Bad Soden, Germany) and homogenized with a tissue lyzer (Qiagen) for $2 \times 2 \mathrm{~min}$ at $30 \mathrm{~Hz}$. Lysates

Table 1 Primer sequences $\left(5^{\prime} \rightarrow 3^{\prime}\right)$

\begin{tabular}{|c|c|c|c|c|}
\hline Gene name & Acc. number & Primer sequence & Product (bp) & $T_{\mathrm{A}}\left({ }^{\circ} \mathrm{C}\right)$ \\
\hline Gclc & NM_010295.1 & $\begin{array}{l}\text { fwd CCGCTGTCCAAGGTTGACGA } \\
\text { rev GTTGCCGCCTTTGCAGATGTC }\end{array}$ & 101 & 60 \\
\hline Gpx2 & NM_030677 & $\begin{array}{l}\text { fwd GTGCTGATTGAGAATGTGGC } \\
\text { rev AGGATGCTCGTTCTGCCCA }\end{array}$ & 252 & 60 \\
\hline Gsta1/a2 & NM_008181.2 & $\begin{array}{l}\text { fwd GCAGACCAGAGCCATTCTCAACT } \\
\text { rev CAAGGTAGTCTTGTCCATGGCTC }\end{array}$ & 247 & 60 \\
\hline Gstm1 & NM_010358.4 & $\begin{array}{l}\text { fwd AGCTCATCATGCTCTGTTACAACC } \\
\text { rev AATCCACATAGGTGACCTTGTCCC }\end{array}$ & 143 & 62 \\
\hline Gstp1 & NM_013541.1 & $\begin{array}{l}\text { fwd CAAATATGTCACCCTCATCTACACCA } \\
\text { rev CAAAGGAGATCTGGTCACCCAC }\end{array}$ & 148 & 62 \\
\hline Hmox 1 & NM_010442.1 & $\begin{array}{l}\text { fwd CCTGGTGCAAGATACTGCCC } \\
\text { rev GAAGCTGAGAGTGAGGACCCA }\end{array}$ & 105 & 60 \\
\hline Mt2 & NM_008630.2 & $\begin{array}{l}\text { fwd CTGTGCCTCCGATGGATCCT } \\
\text { rev CTTGTCGGAAGCCTCTTTGCAG }\end{array}$ & 150 & 62 \\
\hline Nqo1 & NM_008706.4 & $\begin{array}{l}\text { fwd ATGTACGACAACGGTCCTTTCCAG } \\
\text { rev GATGCCACTCTGAATCGGCCA }\end{array}$ & 134 & 60 \\
\hline $\operatorname{Prdx} 1$ & NM_011034.3 & $\begin{array}{l}\text { fwd CAAGTGATTGGCGCTTCTGTGG } \\
\text { rev AATGGTGCGCTTGGGATCTG }\end{array}$ & 122 & 62 \\
\hline Sepw1 & NM_009156.2 & $\begin{array}{l}\text { fwd ATGCCTGGACATTTGTGGCGA } \\
\text { rev GCAGCTTTGATGGCGGTCAC }\end{array}$ & 152 & 60 \\
\hline Sod1 & NM_011434.1 & $\begin{array}{l}\text { fwd GGACAATACACAAGGCTGTACC } \\
\text { rev CAGTCACATTGCCCAGGTCTC }\end{array}$ & 112 & 60 \\
\hline Srxn1 & NM_029688.4 & $\begin{array}{l}\text { fwd AGCCTGGTGGACACGATCCT } \\
\text { rev TGCTGGTAGGCTGCATAGCG }\end{array}$ & 130 & 62 \\
\hline Sult1b1 & NM_019878.3 & $\begin{array}{l}\text { fwd CTGCCCACAGCAATGATGGA } \\
\text { rev GCATCAAATTGCTCAGTTTGGGTC }\end{array}$ & 106 & 62 \\
\hline Txnrd1 & NM_015762.1 & $\begin{array}{l}\text { fwd TACTGCATCAGCAGTGATGATC } \\
\text { rev CCATGTTCTTCCATGTGTTCAC }\end{array}$ & 206 & 60 \\
\hline Ugt1a6a/b & NM_201410 & $\begin{array}{l}\text { fwd CACGTGCTACCTAGAGGCACAG } \\
\text { rev GACCACCAGCAGCTTGTCAC }\end{array}$ & 142 & 62 \\
\hline \multicolumn{5}{|c|}{ Reference genes } \\
\hline Hprt1 & NM_013556 & $\begin{array}{l}\text { fwd GCAGTCCCAGCGTCGTG } \\
\text { rev GGCCTCCCATCTCCTTCAT }\end{array}$ & 168 & 60 \\
\hline Rpl13a & NM_009438 & $\begin{array}{l}\text { fwd GTTCGGCTGAAGCCTACCAG } \\
\text { rev TTCCGTAACCTCAAGATCTGCT }\end{array}$ & 157 & 60 \\
\hline
\end{tabular}


were centrifuged for $15 \mathrm{~min}$ at $21,000 \times g$ and $4^{\circ} \mathrm{C}$ before protein content was assessed according to Bradford [7].

\section{Western blots}

Aliquots (20 $\mu \mathrm{g}$ protein/lane) were subjected to SDSPAGE and blots performed as described [5]. NQO1 was detected with the rabbit-anti-human NQO1 antiserum (1:3,000; ab34173, Abcam, Cambridge, UK). $\beta$-Actin, detected by rabbit-anti-human $\beta$-actin antiserum $(1: 5,000$; ab8229, Abcam), served as internal control. Peroxidaseconjugated anti-rabbit antibody (1:50,000; Chemicon, Hofheim, Germany) was used as secondary antibody. Detection was achieved in a Fuji LAS3000-CCD system with Supersignal West Dura (Perbio, Bonn, Germany) as substrate. Bands were quantified with the Aida/2D densitometry 4.0 software (Raytest, Straubenhardt, Germany).

\section{NQO1 activity}

Dicoumarol-sensitive NQO1 activity was measured according to [42]. Reduction in 3-(4,5-dimethylthiazol-2yl)-2,5-diphenyltetrazolium bromide (MTT) mediated by menadione was followed on a microtiter plate absorbance reader at $590 \mathrm{~nm}$ (Synergy 2, Biotek Instruments $\mathrm{GmbH}$, Bad Friedrichshall, Germany) that corrects different filling levels to $1-\mathrm{cm}$ path length. $3 \mu \mathrm{l}$ lysate was used for the assay together with $190-\mu \mathrm{l}$ reaction buffer $(25 \mathrm{mM}$ Tris-HCl, pH 7.4, $0.665 \mathrm{mg} / \mathrm{l}$ BSA, 0.01\% Tween 20, $5 \mu \mathrm{M}$ FAD, $1 \mathrm{mM}$ glucose-6-phosphate, $30 \mu \mathrm{M}$ NADP, $0.72 \mathrm{mM}$ MTT, $0.3 \mathrm{U} / \mathrm{ml}$ glucose-6-phosphate dehydrogenase, $50 \mu \mathrm{M}$ menadione) in a total volume of $250 \mu \mathrm{l}$. Activity of NQO1 was calculated as the difference between the rates of MTT reduction with and without dicoumarol using an extinction coefficient of reduced MTT estimated to be $11,961(\mathrm{~mol} / \mathrm{l})^{-1} \times \mathrm{cm}^{-1}$ at $590 \mathrm{~nm}$.

\section{Statistical analysis}

Comparing two groups, significant differences were calculated by an unpaired Student's $t$-test (GraphPad Prism ${ }^{\circledR}$ version 5.0, San Diego, CA, USA). A $P$-value of $<0.05$ was regarded as statistically significant.

\section{Results}

Nrf2 target genes respond to selenium supply in the intestine of mice

Microarray analysis revealed that 48 known Nrf2 targets were expressed more than twofold above the background in the colon of mice (Table 2, genes with reference). In addition, 12 classical phase II enzymes but not yet characterized as Nrf2 target genes (in Table 2 without reference) were included in the analysis presented in Table 2, which were up-regulated in marginal selenium-deficiency. Of these 60 genes, 41 were up-regulated $(\mathrm{FC}>1.1$ indicated in bold in Table 2) in marginal selenium-deficiency, whereas 9 were down-regulated $(\mathrm{FC}<0.9)$. The rest was not affected. Nineteen genes for which names are marked bold (Table 2) were analyzed by qPCR. They were either chosen to cover the main enzyme families summarized as phase II enzymes or as typical Nrf2 target genes known from the literature. According to qPCR, 14 genes were significantly regulated in the colon by the selenium supply (Figs. 1, 2 and 3), while 5 genes were unaffected (data not shown). Up-regulation of genes of the antioxidant defense like Hmox1, Mt2, Prdx1, Srxn1, Sod1 and Gclc could be confirmed in the colon (Fig. 1). Expression levels were also analyzed in duodenum as absorption of selenomethionine mainly takes place in the proximal part of the gastrointestinal tract [39]. In fact, except for Mt2, up-regulation in marginal selenium-deficiency was stronger in the duodenum than in the colon, but effects were less significant due to a higher inter-individual variance. Also the six classical phase II enzymes Nqo1, Gsta1/a2, Gstm1, Gstp1, Sult1b1 and Ugt1a6 were up-regulated in selenium-poor colon (Fig. 2). In the duodenum, however, only a trend was observed for Nqo1 and Sult1b1. None of the analyzed genes were changed by the selenium supply in the liver, except Hmox 1, which was, in contrast to the intestine, down-regulated in selenium-poor liver (Table 3 ).

The two Nrf2 selenoprotein target genes, GPx2 and TrxR1, are special cases because their translation depends on selenium availability and their ranking in the hierarchy. The mRNA of both high-ranking selenoproteins GPx2 [57] and TrxR1 [10] was significantly reduced in selenium-poor colon with GPx2 being less affected than TrxR1. In contrast, mRNA of both enzymes was enhanced in seleniumpoor duodenum (Fig. 3a, b). Up-regulation of GPx2 mRNA in selenium-deficiency was already shown in cell culture [57]. The stability of the mRNA under limiting selenium conditions enabled rapid re-synthesis of GPx2 in the selenium-deficient cells upon repletion of selenium [57]. Both observations can be taken as proof for the high ranking of GPx2 in the hierarchy of selenoproteins. The expression of Sepw1, which is not regulated by Nrf2, is down-regulated in the duodenum and colon in accordance with its low ranking in the hierarchy (Fig. 3c).

Up-regulation of NQO1 RNA in selenium-deficient duodenum correlates with NQO1 protein expression and activity

NQO1 as prototype of Nrf2 target genes was further analyzed at the protein and activity level. In duodenum both, 
Table 2 Colon Nrf2 target genes responding to selenium supply as measured by microarray analysis

\begin{tabular}{|c|c|c|c|c|c|}
\hline Gene name & Description & Acc. number & $P$ value & FC & Reference \\
\hline Abcb1a (Mdr3) & ATP-binding cassette, subfamily B (MDR/TAP), member 1A & NM_011076 & 0.139 & 1.11 & \\
\hline Abcb1b (Mdr1) & ATP-binding cassette, subfamily B (MDR/TAP), member 1B & NM_011075 & 0.138 & 1.09 & {$[24]$} \\
\hline Abcc1 (Mrp1) & ATP-binding cassette, subfamily C (CFTR/MRP), member 1 & NM_008576 & 0.0003 & 0.83 & [15] \\
\hline Abcc4 (Mrp4) & ATP-binding cassette, subfamily C (CFTR/MRP), member 4 & NM_001033336 & 0.004 & 1.23 & [36] \\
\hline Abcg5 & ATP-binding cassette, subfamily G (WHITE), member 5 & NM_031884 & 0.028 & 1.22 & {$[47]$} \\
\hline Aldh1a1 & Aldehyde dehydrogenase family 1 , subfamily A1 & NM_013467 & 0.133 & 1.21 & [34] \\
\hline Aldh1a3 & Aldehyde dehydrogenase family 1 , subfamily A3 & NM_053080 & 0.040 & 1.20 & \\
\hline Aldh1a7 & Aldehyde dehydrogenase family 1 , subfamily A7 & NM_011921 & 0.028 & 1.12 & {$[34,47]$} \\
\hline Aldh3a2 & Aldehyde dehydrogenase family 3 , subfamily A2 & NM_007437 & 0.120 & 1.16 & [47] \\
\hline Aldh9a1 & Aldehyde dehydrogenase 9, subfamily A1 & NM_019993 & 0.002 & 1.31 & \\
\hline Blvrb & Biliverdin reductase B (flavin reductase (NADPH)) & NM_144923 & 0.106 & 1.14 & {$[40]$} \\
\hline Cat & Catalase & NM_009804 & 0.760 & 1.03 & {$[11]$} \\
\hline Ces1 & Carboxylesterase 1 & NM_021456 & 0.109 & 1.20 & [47] \\
\hline Ces2 & Carboxylesterase 2 & NM_145603 & 0.004 & 0.72 & [47] \\
\hline Ephx1 & Epoxide hydrolase 1, microsomal & NM_010145 & 0.563 & 1.04 & [6] \\
\hline Esm1 & Endothelial cell-specific molecule 1 & NM_023612 & 0.011 & 1.16 & [41] \\
\hline Fth1 & Ferritin heavy chain 1 & NM_010239 & 0.098 & 1.29 & [41] \\
\hline G6pdx & Glucose-6-phosphate dehydrogenase X-linked & NM_008062 & 0.057 & 1.19 & {$[54]$} \\
\hline Gclc & Glutamate-cysteine ligase, catalytic subunit & NM_010295 & 0.048 & 0.80 & {$[37]$} \\
\hline Gclm & Glutamate-cysteine ligase, modifier subunit & NM_008129 & 0.038 & 0.88 & [37] \\
\hline Gpx2 & Glutathione peroxidase 2 & NM_030677 & 0.065 & 0.67 & {$[5]$} \\
\hline Gsr & Glutathione reductase 1 & NM_010344 & 0.401 & 1.12 & [54] \\
\hline Gss & Glutathione synthetase & NM_008180 & 0.044 & 0.74 & {$[33]$} \\
\hline Gsta1 & Glutathione S-transferase, alpha 1 (Ya) & NM_008181 & 0.264 & 1.15 & [21] \\
\hline Gsta2 & Glutathione S-transferase, alpha 2 (Yc2) & NM_008182 & 0.073 & 1.15 & {$[21]$} \\
\hline Gsta3 & Glutathione S-transferase, alpha 3 & NM_001077353 & 0.329 & 1.12 & {$[21]$} \\
\hline Gsta4 & Glutathione S-transferase, alpha 4 & NM_010357 & 0.001 & 1.18 & {$[21]$} \\
\hline Gstm1 & Glutathione S-transferase, mu 1 & NM_010358 & 0.272 & 1.22 & {$[21]$} \\
\hline Gstm5 & Glutathione S-transferase, mu 5 & NM_010360 & 0.027 & 1.30 & {$[21]$} \\
\hline Gstm7 & Glutathione S-transferase, mu 7 & NM_026672 & 0.080 & 1.29 & \\
\hline Gstp1 & Glutathione S-transferase, pi 1 & NM_013541 & 0.141 & 0.80 & [19] \\
\hline Gusb & Glucuronidase, beta & ВС004616 & 0.013 & 1.15 & \\
\hline Hmox1 & Heme oxygenase (decycling) 1 & NM_010442 & 0.025 & 1.09 & [11] \\
\hline Mt1 & Metallothionein 1 & NM_013602 & 0.010 & 1.32 & [59] \\
\hline Mt2 & Metallothionein 2 & NM_008630 & 0.019 & 1.57 & [59] \\
\hline Nat13 & $\mathrm{N}$-acetyltransferase 13 & NM_028108 & 0.001 & 1.21 & \\
\hline Nat3 & $\mathrm{N}$-acetyltransferase 3 & NM_008674 & 0.002 & 1.29 & \\
\hline Nat8 1 & $\mathrm{~N}$-acetyltransferase 8 -like & NM_001001985 & 0.038 & 1.15 & \\
\hline Nqo1 & NAD(P)H dehydrogenase, quinone 1 & NM_008706 & 0.589 & 1.04 & {$[11,56]$} \\
\hline Pgd & Phosphogluconate dehydrogenase & ВC011329 & 0.007 & 0.72 & [54] \\
\hline Pir & Pirin & NM_027153 & 0.312 & 1.10 & [18] \\
\hline Prdx1 & Peroxiredoxin 1 & NM_011034 & 0.092 & 1.32 & {$[20,27]$} \\
\hline $\operatorname{Prdx} 2$ & Peroxiredoxin 2 & NM_011563 & 0.229 & 1.20 & \\
\hline Prdx4 & Peroxiredoxin 4 & NM_016764 & 0.026 & 1.34 & \\
\hline Sod1 & Superoxide dismutase 1 , soluble & NM_011434 & 0.012 & 1.54 & [11] \\
\hline Sqstm1 & Sequestosome 1 (A170 stress protein) & NM_011018 & 0.037 & 1.28 & {$[20]$} \\
\hline Srxn1 & Sulfiredoxin 1 homolog & NM_029688 & 0.128 & 1.17 & [4] \\
\hline Sult1b1 & Sulfotransferase family $1 \mathrm{~B}$, member 1 & NM_019878 & 0.016 & 1.26 & [2] \\
\hline
\end{tabular}


Table 2 continued

\begin{tabular}{|c|c|c|c|c|c|}
\hline Gene name & Description & Acc. number & $P$ value & $\mathrm{FC}$ & Reference \\
\hline Sult1c2 & Sulfotransferase family, cytosolic, 1C, member 2 & NM_026935 & 0.039 & 1.21 & {$[2]$} \\
\hline Tkt & Transketolase & NM_009388 & 0.904 & 1.01 & {$[18]$} \\
\hline Txn1 & Thioredoxin 1 & NM_011660 & 0.377 & 1.11 & [26] \\
\hline Txn2 & Thioredoxin, mitochondrial protein & U85089 & 0.154 & 1.12 & [26] \\
\hline Txnrd1 & Thioredoxin reductase 1 (Txnrd1), transcript variant 1 & NM_001042523 & 0.572 & 0.94 & [17] \\
\hline Ugdh & UDP-glucose dehydrogenase & NM_009466 & 0.300 & 1.14 & [47] \\
\hline Ugp2 & UDP-glucose pyrophosphorylase 2 & NM_139297 & 0.753 & 1.02 & [47] \\
\hline Ugt1a1 & UDP glucuronosyltransferase 1 family, polypeptide A1 & NM_201645 & 0.981 & 1.00 & {$[60]$} \\
\hline Ugt1a6b & UDP glucuronosyltransferase 1 family, polypeptide A6B & NM_201410 & 0.217 & 1.26 & [11] \\
\hline Ugt2b34 & UDP glucuronosyltransferase 2 family, polypeptide B34 & NM_153598 & 0.004 & 0.82 & {$[47]$} \\
\hline Ugt2b37 & UDP glucuronosyltransferase 2 family, polypeptide B37 & NM_053215 & 0.009 & 1.26 & \\
\hline Ugt2b5 & UDP glucuronosyltransferase 2 family, polypeptide B5 & NM_009467 & 0.020 & 1.20 & \\
\hline
\end{tabular}

Genes are sorted based on gene name. Fold change (FC) numbers in bold indicate an up-regulation in selenium-deficiency (FC $>1.1)$. Gene names in bold indicate analysis by qPCR. Gene names in italic point to selenoprotein genes

NQO1 protein and activity, were significantly enhanced in the selenium-poor group (Fig. 4), correlating with the enhanced mRNA (Fig. 2a). In the colon, neither protein levels nor activity were changed, indicating that the slight increase of NQO1 mRNA is not reflected by an increased translation and activity.

\section{Discussion}

The present study is part of an animal experiment in which mice were fed a selenium-adequate diet meeting the RDA for mice or a diet in which the selenium content was reduced to about 50\% [28]. Although the selenium intake was only moderately reduced, the RNA expression of four selenoproteins, SelW, GPx1, SelH and SelM, was distinctly down-regulated and genes of the Wnt pathway were upregulated in the colon [28]. A manual analysis of the microarray data revealed that also Nrf2 target genes and phase II enzymes were regulated by the selenium status; out of 60 genes expressed in the colon, 41 were up-regulated accounting for $68 \%$ (Table 2). The expression of 12 selected genes for antioxidant defense and phase II enzymes was confirmed by qPCR (Figs. 1 and 2). The consistent up-regulation of Nrf2 target genes in marginal selenium-deficiency is highly relevant since a suboptimal selenium supply may also result from a low selenium diet often consumed by humans [45]. The establishment of a marginal selenium-deficiency is in contrast to most of the other studies investigating the effects of either high selenium supplementation or severe selenium-deficiency.

Also Burk and colleagues, who provided the first direct link between dietary selenium-deficiency and Nrf2 activation, compared mice fed either a completely selenium- deficient or a -supplemented diet with $0.25 \mathrm{mg}$ sodium selenite per $\mathrm{kg}$ [9]. Under selenium-deficient conditions, ARE-driven reporter gene activity as well as GST and NQO1 activity were strongly increased in the liver of wild-type mice but were unchanged in $\mathrm{Nrf} 2^{-1-}$ mice. The current study revealed that already a marginal seleniumdeficiency can lead to an up-regulation of phase II enzymes underscoring how sensitive organisms are to changes in selenium homeostasis.

As Nrf2 target gene expression was unaffected by a marginal selenium-deficiency in the liver (Table 3), but upregulated in the intestine, it can be concluded that the intestine reacts more sensitively to a reduced selenium supply. In the liver of $\mathrm{Nrf} 2^{-1-}$ mice, most of the known Nrf2 target genes were down-regulated, whereas mainly enzymes for detoxification were increased in Keap1 knockdown mice characterized by an increased Nrf2 activation [47]. The authors conclude that the hepatic activation of Nrf2 is more important for detoxification than for antioxidant defense. In the current study, a distinct up-regulation of enzymes for the antioxidant defense was observed in the duodenum. Since a reduced redox state maintains intestinal epithelial cell proliferation and prevents pre-mature apoptosis [3], a higher need for enzymes of the antioxidant defense can explain the present findings.

However, also contrary findings have been reported: Detoxifying genes were down-regulated by selenium-deficiency when feeding $0.01 \mathrm{mg}$ selenium $/ \mathrm{kg}$ diet or $1 \mathrm{mg} / \mathrm{kg}$ [44]. Thus, the selenium content differed by a factor of 100 , whereas in the present study the factor was only 2 . The conflicting results (reviewed in [13]) can be explained by the fact that a supranutritional diet can induce phase II enzymes much more efficiently than selenium-deficiency can do. Taking the supranutritional diet as reference for the 
(A) Hmox1 colon

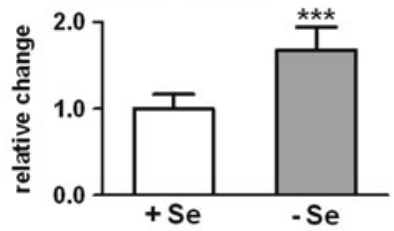

(B) Mt2

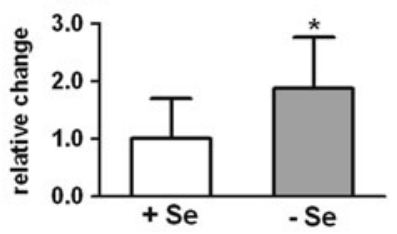

(C) $\operatorname{Prdx1}$

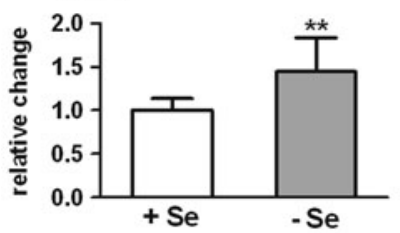

(D) Srxn1

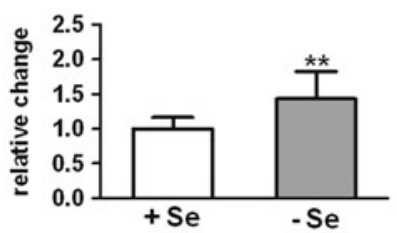

(E) Sod1

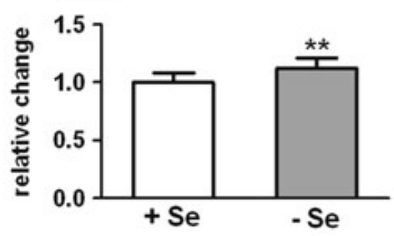

(F) ${ }_{\text {Gclc }}$

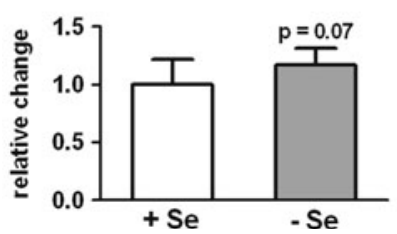

duodenum
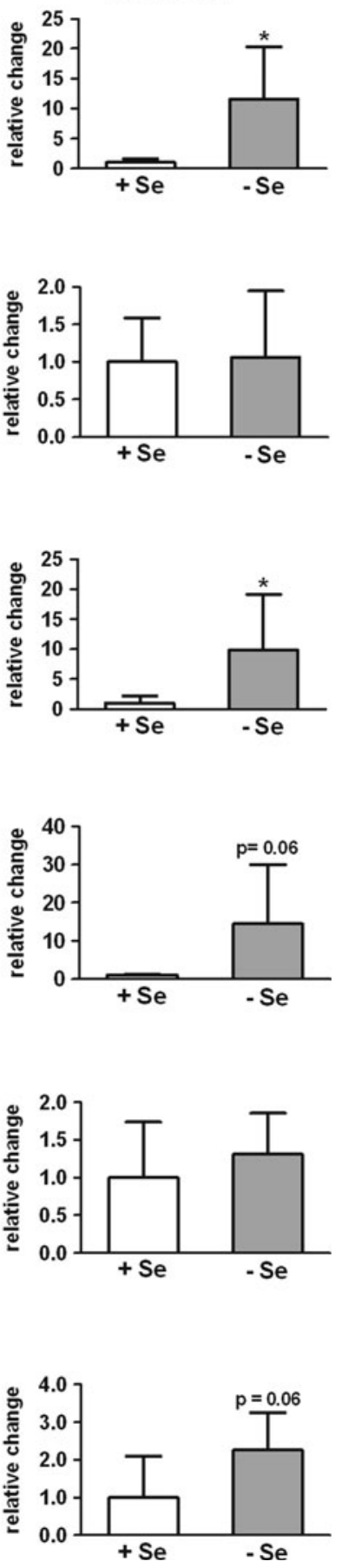

Fig. 1 mRNA expression of antioxidant enzymes in the colon $(n=9)$ and duodenum $(n=6)$ of selenium-poor $(-\mathrm{Se})$ relative to seleniumadequate $(+\mathrm{Se})$ mice. a Heme oxygenase $1(\mathrm{Hmox} 1)$, b metallothionein 2 (Mt2), c peroxiredoxin $1(\operatorname{Prdx} 1)$, d sulfiredoxin 1 (Srxn1), e superoxide dismutase 1 ( $\operatorname{Sod} 1)$, f $\gamma$-glutamylcysteine synthetase, catalytic subunit (Gclc). Gene expression was analyzed by qPCR and normalized to Rpl13a in the duodenum and to the mean of the reference genes Hprt1 and Rpl13a in the colon. $* P<0.05$; $* * P<0.01$; $* * * P<0.001$ versus + Se set to 1 analyzed by unpaired Student's $t$-test
(A) $\mathrm{NqO1}$ colon
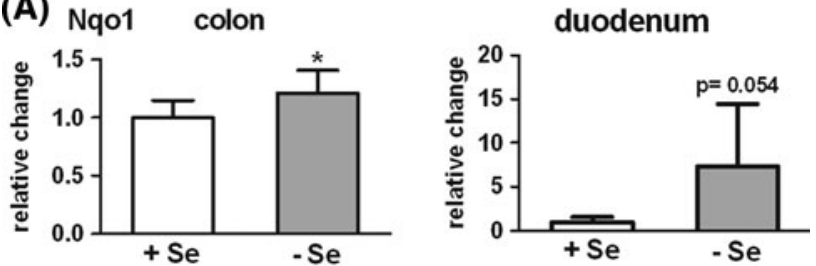

(B) Gsta1/a2
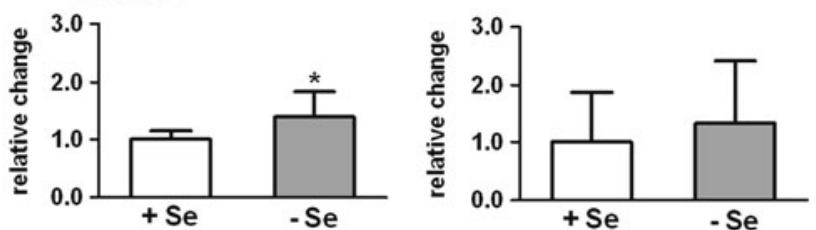

(C) Gstm1
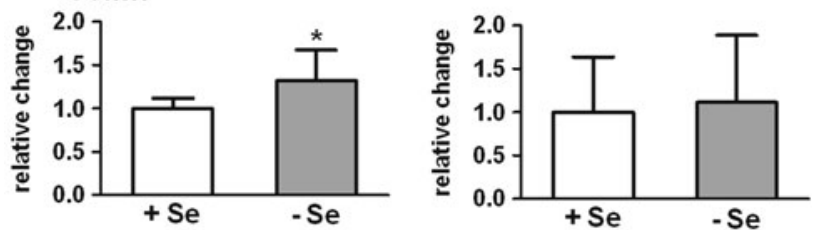

(D) Gstp1
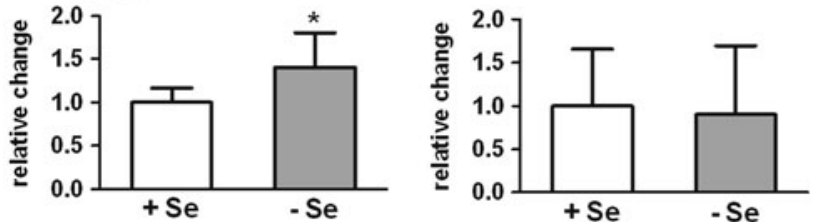

(E)
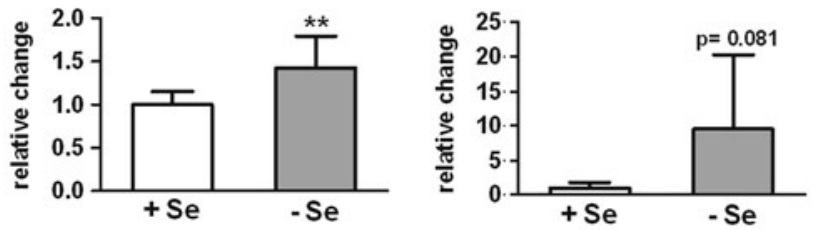

(F)

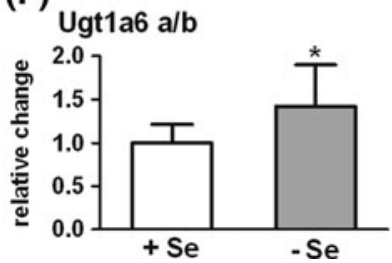

not detectable

Fig. 2 mRNA expression of phase II enzymes in the colon $(n=9)$ and duodenum $(n=6)$ of selenium-poor $(-\mathrm{Se})$ relative to seleniumadequate $(+\mathrm{Se})$ mice. a NADPH:quinone oxidoreductase (Nqo1), b glutathione S-transferase a1/a2 (Gsta1/a2), c glutathione S-transferase $\mathrm{m} 1$ (Gstm1), d glutathione S-transferase p1 (Gstp1), e sulfotransferase $1 \mathrm{~b} 1$ (Sult1b1), f UDP glucuronosyltransferase 1a6 a/b (Ugt1a6 $\mathrm{a} / \mathrm{b})$. Gene expression was analyzed by qPCR and normalized to Rpl13a in the duodenum and to the mean of the reference genes Hprt1 and Rpl13a in the colon. $* P<0.05$; $* * P<0.01$; versus + Se set to 1 analyzed by unpaired Student's $t$-test 
(A) Txnrd1 colon

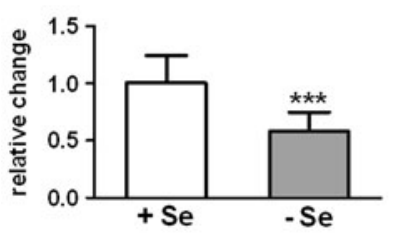

(B) Gpx2

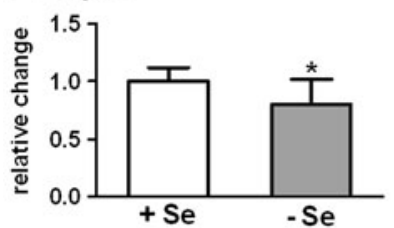

(C) Sepw1

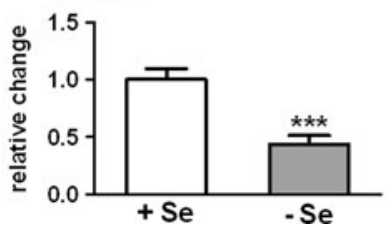

duodenum
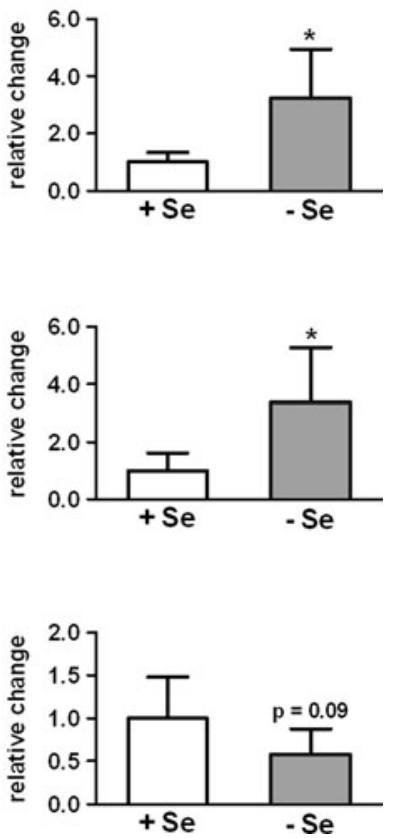

Fig. 3 mRNA expression of selenoproteins in the colon $(n=9)$ and duodenum $(n=6)$ of selenium-poor $(-\mathrm{Se})$ relative to seleniumadequate $(+\mathrm{Se})$ mice. a Thioredoxin reductase 1 (Txnrd1), b glutathione peroxidase 2 (Gpx2), c selenoprotein W (Sepw1). Gene expression was analyzed by qPCR and normalized to Rpl13a in the duodenum and to the mean of the reference genes Hprt1 and Rpl13a in the colon. $* P<0.05$; $* * P<0.01$; versus + Se set to 1 analyzed by unpaired Student's $t$-test

Table 3 qPCR results of Nrf2 target genes and phase II enzymes analyzed in the liver

\begin{tabular}{lll}
\hline Gene & FC $-\mathrm{Se} /+\mathrm{Se}$ & $P$ value \\
\hline Hmox1 & 0.68 & 0.04 \\
Mt2 & 1.01 & 0.98 \\
Prdx1 & 1.07 & 0.56 \\
Srxn1 & 1.00 & 0.99 \\
Sod1 & 1.12 & 0.15 \\
Gclc & 0.96 & 0.79 \\
Nqo1 & 1.06 & 0.63 \\
Gsta1/a2 & 0.94 & 0.63 \\
Gstm1 & 1.14 & 0.42 \\
Gstp1 & 1.09 & 0.55 \\
Sult1b1 & 0.98 & 0.89 \\
Ugt1a6 a/b & 0.91 & 0.55 \\
\hline
\end{tabular}

Fold change (FC) of the mRNA expression in the liver $(n=9)$ of selenium-poor $(-\mathrm{Se})$ relative to selenium-adequate $(+\mathrm{Se})$ mice. The $P$-value was analyzed by unpaired Student's $t$-test

deficient one, the net effect is a down-regulation in selenium-deficiency.

Underlying mechanisms for the effects of low and high selenium content appear to be different. High concentrations

(A) NQO1 Western Blot

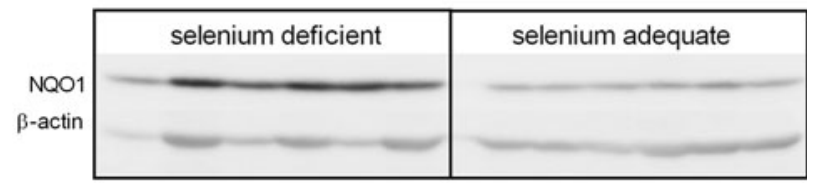

(B) NQO1 protein

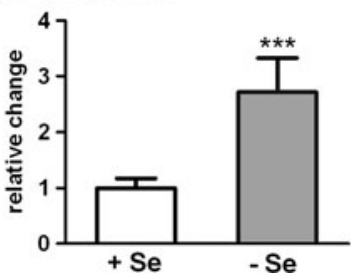

(C) NQO1 activity

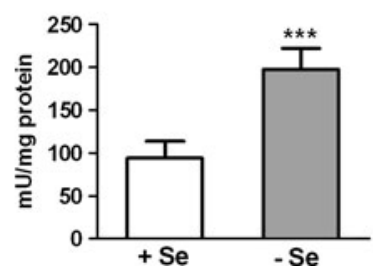

Fig. 4 NQO1 protein expression and activity in the duodenum of mice. Protein was measured by Western Blot (a), densitometrically analyzed and normalized to $\beta$-actin (b). Absolute NQO1 activity was measured via the reduction in MTT (c). Values are means of six animals per group \pm standard deviation. $* * * P<0.001$ versus $+\mathrm{Se}$ analyzed by unpaired Student's $t$-test. See "Materials and Methods" for further details

of certain selenium compounds or metabolites may directly activate the Nrf2 pathway by modifying critical thiols in Keap1. Reactive thiol groups can also be modified by oxidation $[22,29]$ a situation which prevails in selenium-deficiency $[52,55]$. Whether a higher oxidative status in the moderately selenium-deficient mice was responsible for the induced Nrf2 target gene expression needs to be clarified.

The complete loss of all selenoproteins by the knockout of the gene for the Sec-specific tRNA (Trsp) in hepatocytes enhanced the expression of several phase II enzymes, indicating that at least one selenoprotein normally suppresses the activation of the Nrf2 pathway [50]. To lower the number of putative candidates, Sengupta and colleagues used a second mouse strain in which Trsp was mutated in a way that only housekeeping but not stress-related selenoproteins were expressed. These mice did not respond with a compensatory up-regulation of phase II enzymes, indicating that a housekeeping selenoprotein must prevent Nrf2 activation [50]. Since the thioredoxin reductase family belongs to the housekeeping selenoproteins [10], a liver-specific TrxR1 knockout was analyzed for potential activation of the Nrf2 pathway. Indeed, the TrxR1 knockout resulted in both, the nuclear accumulation of $\mathrm{Nrf} 2$ and the induction of $21 \mathrm{Nrf} 2$ target genes [51]. mRNA levels of TrxR2, TrxR3 or thioredoxin were unaffected. Thus, TrxR1 appears to counteract Nrf2 activation and/or serves as a turn-off signal for Nrf2 activation. However, TrxR1-deficient livers did not show evidence of oxidative stress, leaving the underlying mechanism unclear [51].

Selenium also influences the expression of multiple genes coding for non-selenoproteins, which might be involved in the specific activation of the Nrf2 pathway 
under marginal selenium-deficiency. In the previous study [28], we found the Wnt pathway activated, indicated by the enhanced expression of $\beta$-catenin, Dvl2, Lef1 and c-Myc and the down-regulation of $\operatorname{Gsk} 3 \beta$. GSK3 $\beta$, a multifunctional serine/threonine kinase, is not only involved in glycogen metabolism and canonical Wnt signaling but has also been shown to inactivate the Nrf2 pathway [23, 49]. Fyn kinase is phosphorylated and thereby activated by GSK3 $\beta$. Phospho-Fyn, in turn, phosphorylates Nrf2 resulting in the nuclear export of Nrf2 [23]. The reduced activity of GSK $3 \beta$, which may be deduced from the downregulation of Gsk $3 \beta$ under selenium-limiting conditions in the previous study, might lower the amount of active Fyn resulting in nuclear accumulation of $\mathrm{Nrf} 2$.

The activation of the Nrf2 pathway in marginal selenium-deficiency is relevant in terms of colorectal cancer development. In a model of inflammation-triggered colorectal carcinogenesis, $\mathrm{Nrf}^{-/-}$mice showed an increased incidence, multiplicity and tumor size compared to wild type mice [25]. On the one hand, phase II enzymes like the GST, SULT and UGT family are involved in the conjugation and excretion of xenobiotic substances. Together with the up-regulation of genes for antioxidant enzymes like peroxiredoxins, sulfiredoxin, Sod1, Hmox1 and metallothionein, the organism is protected from oxidative damage. On the other hand, the Nrf2 activation may also contribute to an increased drug export, to drug resistance and to tumor cell survival $[16,31]$. Therefore, the consequence of an up-regulation of Nrf2 target genes for colorectal cancer in selenium-deficiency can not be easily defined. The activation of the Wnt pathway in seleniumdeficiency points to a cancer-promoting function of a lowselenium status and is in accordance with the higher cancer incidence in selenium-deficiency (reviewed in [46]). Whether the activation of the Nrf2 pathway is the attempt to compensate for the loss of selenoproteins with the strengthening of the endogenous defense system or whether it already contributes to survival of cancer cells is a challenge for further investigations.

Acknowledgments We thank Stefanie Deubel for excellent technical assistance and the team of the animal facilities, especially Elke Thom and Swetlana König. Evert van Schothorst and Jaap Keijer (Human and Animal Physiology, Wageningen University, The Netherlands) are acknowledged for their help in performing the microarray analysis. The work was financially supported by the European Nutrigenomics Organisation (NUGO) and the German Research Council (DFG), grant Br778/8-1.

\section{References}

1. Aleksunes LM, Manautou JE (2007) Emerging role of Nrf2 in protecting against hepatic and gastrointestinal disease. Toxicol Pathol 35:459-473
2. Alnouti Y, Klaassen CD (2008) Tissue distribution, ontogeny, and regulation of aldehyde dehydrogenase (Aldh) enzymes mRNA by prototypical microsomal enzyme inducers in mice. Toxicol Sci 101:51-64

3. Aw TY (2003) Cellular redox: a modulator of intestinal epithelial cell proliferation. News Physiol Sci 18:201-204

4. Bae SH, Woo HA, Sung SH, Lee HE, Lee SK, Kil IS, Rhee SG (2009) Induction of sulfiredoxin via an Nrf2-dependent pathway and hyperoxidation of peroxiredoxin III in the lungs of mice exposed to hyperoxia. Antioxid Redox Signal 11:937-948

5. Banning A, Deubel S, Kluth D, Zhou Z, Brigelius-Flohé R (2005) The GI-GPx gene is a target for Nrf2. Mol Cell Biol 25:49144923

6. Benson AM, Cha YN, Bueding E, Heine HS, Talalay P (1979) Elevation of extrahepatic glutathione S-transferase and epoxide hydratase activities by 2(3)-tert-butyl-4-hydroxyanisole. Cancer Res 39:2971-2977

7. Bradford MM (1976) A rapid and sensitive method for the quantitation of microgram quantities of protein utilizing the principle of protein-dye binding. Anal Biochem 72:248-254

8. Brigelius-Flohé R (1999) Tissue-specific functions of individual glutathione peroxidases. Free Radic Biol Med 27:951-965

9. Burk RF, Hill KE, Nakayama A, Mostert V, Levander XA, Motley AK, Johnson DA, Johnson JA, Freeman ML, Austin LM (2008) Selenium deficiency activates mouse liver Nrf2-ARE but vitamin E deficiency does not. Free Radic Biol Med 44:16171623

10. Carlson BA, Moustafa ME, Sengupta A, Schweizer U, Shrimali R, Rao M, Zhong N, Wang S, Feigenbaum L, Lee BJ, Gladyshev VN, Hatfield DL (2007) Selective restoration of the selenoprotein population in a mouse hepatocyte selenoproteinless background with different mutant selenocysteine tRNAs lacking Um34. J Biol Chem 282:32591-32602

11. Chan K, Kan YW (1999) Nrf2 is essential for protection against acute pulmonary injury in mice. Proc Natl Acad Sci USA 96:12731-12736

12. Correia MA, Burk RF (1976) Hepatic heme metabolism in selenium-deficient rats: effect of phenobarbital. Arch Biochem Biophys 177:642-644

13. El-Bayoumy K, Sinha R (2005) Molecular chemoprevention by selenium: a genomic approach. Mutat Res 591:224-236

14. Gromer S, Urig S, Becker K (2004) The thioredoxin system-from science to clinic. Med Res Rev 24:40-89

15. Hayashi A, Suzuki H, Itoh K, Yamamoto M, Sugiyama Y (2003) Transcription factor Nrf2 is required for the constitutive and inducible expression of multidrug resistance-associated protein 1 in mouse embryo fibroblasts. Biochem Biophys Res Commun 310:824-829

16. Hayes JD, McMahon M (2009) NRF2 and KEAP1 mutations: permanent activation of an adaptive response in cancer. Trends Biochem Sci 34:176-188

17. Hintze KJ, Keck AS, Finley JW, Jeffery EH (2003) Induction of hepatic thioredoxin reductase activity by sulforaphane, both in Hepa1c1c7 cells and in male Fisher 344 rats. J Nutr Biochem 14:173-179

18. Hübner RH, Schwartz JD, De Bishnu P, Ferris B, Omberg L, Mezey JG, Hackett NR, Crystal RG (2009) Coordinate control of expression of Nrf2-modulated genes in the human small airway epithelium is highly responsive to cigarette smoking. Mol Med 15:203-219

19. Ikeda H, Serria MS, Kakizaki I, Hatayama I, Satoh K, Tsuchida S, Muramatsu M, Nishi S, Sakai M (2002) Activation of mouse Pi-class glutathione S-transferase gene by Nrf2(NF-E2-related factor 2) and androgen. Biochem J 364:563-570

20. Ishii $\mathrm{T}$, Itoh $\mathrm{K}$, Takahashi $\mathrm{S}$, Sato $\mathrm{H}$, Yanagawa $\mathrm{T}$, Katoh $\mathrm{Y}$, Bannai S, Yamamoto M (2000) Transcription factor Nrf2 
coordinately regulates a group of oxidative stress-inducible genes in macrophages. J Biol Chem 275:16023-16029

21. Itoh K, Chiba T, Takahashi S, Ishii T, Igarashi K, Katoh Y, Oyake T, Hayashi N, Satoh K, Hatayama I, Yamamoto M, Nabeshima Y (1997) An Nrf2/small Maf heterodimer mediates the induction of phase II detoxifying enzyme genes through antioxidant response elements. Biochem Biophys Res Commun 236:313-322

22. Itoh K, Wakabayashi N, Katoh Y, Ishii T, Igarashi K, Engel JD, Yamamoto M (1999) Keap1 represses nuclear activation of antioxidant responsive elements by Nrf2 through binding to the amino-terminal Neh2 domain. Genes Dev 13:76-86

23. Jain AK, Jaiswal AK (2007) GSK-3beta acts upstream of Fyn kinase in regulation of nuclear export and degradation of NF-E2 related factor 2. J Biol Chem 282:16502-16510

24. Jigorel E, Le Vee M, Boursier-Neyret C, Parmentier Y, Fardel O (2006) Differential regulation of sinusoidal and canalicular hepatic drug transporter expression by xenobiotics activating drug-sensing receptors in primary human hepatocytes. Drug Metab Dispos 34:1756-1763

25. Khor TO, Huang MT, Prawan A, Liu Y, Hao X, Yu S, Cheung WK, Chan JY, Reddy BS, Yang CS, Kong AN (2008) Increased susceptibility of Nrf2 knockout mice to colitis-associated colorectal cancer. Cancer Prev Res 1:187-191

26. Kim YC, Yamaguchi Y, Kondo N, Masutani H, Yodoi J (2003) Thioredoxin-dependent redox regulation of the antioxidant responsive element (ARE) in electrophile response. Oncogene 22:1860-1865

27. Kim YJ, Ahn JY, Liang P, Ip C, Zhang Y, Park YM (2007) Human prx1 gene is a target of Nrf2 and is up-regulated by hypoxia/reoxygenation: implication to tumor biology. Cancer Res 67:546-554

28. Kipp A, Banning A, van Schothorst EM, Meplan C, Schomburg L, Evelo C, Coort S, Gaj S, Keijer J, Hesketh J, Brigelius-Flohé R (2009) Four selenoproteins, protein biosynthesis, and Wnt signalling are particularly sensitive to limited selenium intake in mouse colon. Mol Nutr Food Res 53:1561-1572

29. Kobayashi A, Kang MI, Watai Y, Tong KI, Shibata T, Uchida K, Yamamoto M (2006) Oxidative and electrophilic stresses activate Nrf2 through inhibition of ubiquitination activity of Keap1. Mol Cell Biol 26:221-229

30. Kryukov GV, Castellano S, Novoselov SV, Lobanov AV, Zehtab O, Guigo R, Gladyshev VN (2003) Characterization of mammalian selenoproteomes. Science 300:1439-1443

31. Lau A, Villeneuve NF, Sun Z, Wong PK, Zhang DD (2008) Dual roles of Nrf2 in cancer. Pharmacol Res 58:262-270

32. Lawrence RA, Parkhill LK, Burk RF (1978) Hepatic cytosolic non selenium-dependent glutathione peroxidase activity: its nature and the effect of selenium deficiency. J Nutr 108:981987

33. Lee TD, Yang H, Whang J, Lu SC (2005) Cloning and characterization of the human glutathione synthetase 5 '-flanking region. Biochem J 390:521-528

34. Leonard MO, Kieran NE, Howell K, Burne MJ, Varadarajan R, Dhakshinamoorthy S, Porter AG, O'Farrelly C, Rabb H, Taylor CT (2006) Reoxygenation-specific activation of the antioxidant transcription factor Nrf2 mediates cytoprotective gene expression in ischemia-reperfusion injury. FASEB J 20:2624-2626

35. Lu J, Holmgren A (2009) Selenoproteins. J Biol Chem 284:723727

36. Maher JM, Dieter MZ, Aleksunes LM, Slitt AL, Guo G, Tanaka Y, Scheffer GL, Chan JY, Manautou JE, Chen Y, Dalton TP, Yamamoto M, Klaassen CD (2007) Oxidative and electrophilic stress induces multidrug resistance-associated protein transporters via the nuclear factor-E2-related factor-2 transcriptional pathway. Hepatology 46:1597-1610
37. Moinova HR, Mulcahy RT (1998) An electrophile responsive element (EpRE) regulates beta-naphthoflavone induction of the human gamma-glutamylcysteine synthetase regulatory subunit gene. Constitutive expression is mediated by an adjacent AP-1 site. J Biol Chem 273:14683-14689

38. Nguyen T, Nioi P, Pickett CB (2009) The Nrf2-antioxidant response element signaling pathway and its activation by oxidative stress. J Biol Chem 284:13291-13295

39. Ochoa-Solano A, Gitler C (1968) Digestion and absorption of ingested and secreted proteins labeled with $75 \mathrm{Se}$-selenomethionine and 35S-methionine in the gastrointestinal tract of the rat. J Nutr 94:249-255

40. Osburn WO, Yates MS, Dolan PD, Chen S, Liby KT, Sporn MB, Taguchi K, Yamamoto M, Kensler TW (2008) Genetic or pharmacologic amplification of nrf2 signaling inhibits acute inflammatory liver injury in mice. Toxicol Sci 104:218-227

41. Pietsch EC, Chan JY, Torti FM, Torti SV (2003) Nrf2 mediates the induction of ferritin $\mathrm{H}$ in response to xenobiotics and cancer chemopreventive dithiolethiones. J Biol Chem 278:2361-2369

42. Prochaska HJ, Santamaria AB (1988) Direct measurement of $\mathrm{NAD}(\mathrm{P}) \mathrm{H}$ :quinone reductase from cells cultured in microtiter wells: a screening assay for anticarcinogenic enzyme inducers. Anal Biochem 169:328-336

43. Ramos-Gomez M, Kwak MK, Dolan PM, Itoh K, Yamamoto M, Talalay P, Kensler TW (2001) Sensitivity to carcinogenesis is increased and chemoprotective efficacy of enzyme inducers is lost in nrf 2 transcription factor-deficient mice. Proc Natl Acad Sci USA 98:3410-3415

44. Rao L, Puschner B, Prolla TA (2001) Gene expression profiling of low selenium status in the mouse intestine: transcriptional activation of genes linked to DNA damage, cell cycle control and oxidative stress. J Nutr 131:3175-3181

45. Rayman MP (2000) The importance of selenium to human health. Lancet 356:233-241

46. Rayman MP (2005) Selenium in cancer prevention: a review of the evidence and mechanism of action. Proc Nutr Soc 64:527542

47. Reisman SA, Yeager RL, Yamamoto M, Klaassen CD (2009) Increased Nrf2 activation in livers from Keap1-knockdown mice increases expression of cytoprotective genes that detoxify electrophiles more than those that detoxify reactive oxygen species. Toxicol Sci 108:35-47

48. Rushmore TH, Morton MR, Pickett CB (1991) The antioxidant responsive element. Activation by oxidative stress and identification of the DNA consensus sequence required for functional activity. J Biol Chem 266:11632-11639

49. Salazar M, Rojo AI, Velasco D, de Sagarra RM, Cuadrado A (2006) Glycogen synthase kinase-3beta inhibits the xenobiotic and antioxidant cell response by direct phosphorylation and nuclear exclusion of the transcription factor Nrf2. J Biol Chem 281:14841-14851

50. Sengupta A, Carlson BA, Weaver JA, Novoselov SV, Fomenko DE, Gladyshev VN, Hatfield DL (2008) A functional link between housekeeping selenoproteins and phase II enzymes. Biochem J 413:151-161

51. Suvorova ES, Lucas O, Weisend CM, Rollins MF, Merrill GF, Capecchi MR, Schmidt EE (2009) Cytoprotective Nrf2 pathway is induced in chronically txnrd 1-deficient hepatocytes. PLoS One 4:e6158

52. Suzuki T, Kelly VP, Motohashi H, Nakajima O, Takahashi S, Nishimura S, Yamamoto M (2008) Deletion of the Selenocysteine tRNA Gene in Macrophages and Liver Results in Compensatory Gene Induction of Cytoprotective Enzymes by Nrf2. J Biol Chem 283:2021-2030

53. t' Hoen PA, Rooseboom M, Bijsterbosch MK, van Berkel TJ, Vermeulen NP, Commandeur JN (2002) Induction of glutathione- 
S-transferase mRNA levels by chemopreventive selenocysteine Se-conjugates. Biochem Pharmacol 63:1843-1849

54. Thimmulappa RK, Mai KH, Srisuma S, Kensler TW, Yamamoto M, Biswal S (2002) Identification of Nrf2-regulated genes induced by the chemopreventive agent sulforaphane by oligonucleotide microarray. Cancer Res 62:5196-5203

55. Trigona WL, Mullarky IK, Cao Y, Sordillo LM (2006) Thioredoxin reductase regulates the induction of haem oxygenase-1 expression in aortic endothelial cells. Biochem J 394:207-216

56. Venugopal R, Jaiswal AK (1996) Nrf1 and Nrf2 positively and c-Fos and Fra1 negatively regulate the human antioxidant response element-mediated expression of $\mathrm{NAD}(\mathrm{P}) \mathrm{H}$ :quinone oxidoreductase1 gene. Proc Natl Acad Sci USA 93:14960-14965
57. Wingler K, Böcher M, Flohé L, Kollmus H, Brigelius-Flohé R (1999) mRNA stability and selenocysteine insertion sequence efficiency rank gastrointestinal glutathione peroxidase high in the hierarchy of selenoproteins. Eur J Biochem 259:149-157

58. Xiao H, Parkin KL (2006) Induction of phase II enzyme activity by various selenium compounds. Nutr Cancer 55:210-223

59. Yeh CT, Yen GC (2005) Effect of sulforaphane on metallothionein expression and induction of apoptosis in human hepatoma HepG2 cells. Carcinogenesis 26:2138-2148

60. Yueh MF, Tukey RH (2007) Nrf2-Keap1 signaling pathway regulates human UGT1A1 expression in vitro and in transgenic UGT1 mice. J Biol Chem 282:8749-8758 